\title{
MEDICINE AND SOCIAL SCIENCE
}

\author{
THE GEORGE FREDERIC STILL MEMORIAL LECTURE
}

\author{
BY \\ F. A. E. CREWE \\ From the Department of Public Health and Social and Preventive Medicine, University of Edinburgh
}

Everyone of us strives, each in his own fashion, to reach a goal of his own choosing. But since most of the objectives selected are without real or permanent value and since most of us, in our ignorance, choose wrongly, the fortunate among us are, more often than not, they who fail to secure that which they have sought. In each of us a wish for continuance is active; in each of us there lurks a hope that what we do may add significantly to the sum total of the knowledge that in application facilitates the enlargement of human dignity. Every one of us is required to make his contribution towards the well-being of the community of which he is a member and fortunate is the rare individual who from his work derives the maximum of intellectual and emotional satisfaction.

Thoughts such as these are evoked on occasions such as this when we meet to memorialize a man who as an organism underwent dissolution 14 years ago, yet who, as an influence upon thought and action in the field of paediatrics, is still powerful. We are met to refresh our memories of George Frederic Still, once more to pay tribute, minted of deep respect and sincere regard, to one who by the exceptional quality of his personality and of his work rendered outstanding service to mankind, to this Association and to our profession. In the mirror of the dreams of each of us it is his image that we see, for he was what each of us would like to be, a complete man.

That which a man does is what he thinks and what he thinks is the reflection of his ethos and of his own concepts of the nature of the universe and of man's destiny. From the testimony of those who knew him intimately, Still firmly adhered to the Christian faith and modelled his behaviour upon its teachings. From his career, as depicted in his publications, we conclude that he was possessed of an intellectual ability and of a scholarship of more than average quality and that these were exercised with unusual diligence. These qualities in combination are not uncommon within our profession and are not enough in themselves, therefore, to account for
Still's exceptional professional and social status. This can only be explained when Still is studied against the background of his time. It so chanced that Still, reaching his professional maturity, entered a particular field of medical interest and activity at a time when this was about to undergo swift enlargement, to encounter in it abundant opportunity for the exercise of his talents. But why did it so happen that he entered this particular field?

We know that from Caius College, Cambridge, where he took his degree in the Classical Tripos with first-class honours, he went to Guy's Hospital, there to become exposed to, and, being what he was, to react to the stimulus that was James Goodhart. It would seem that it was this encounter that gave direction to his ambition. That is how paediatricians are, or should be, made; inclination, unexpressed and possibly unsuspected, becoming revealed as the student reacts to the peculiar attractions of the subject as these are displayed by a teacher who finds in the advancement of his subject deep and abiding satisfaction.

Here I would remark that possibly the greatest contribution a paediatrician can make to his subject is that of attracting to it young men better equipped in respect of general ability than he is himself. Every one of you can provide a reason to explain why you became paediatricians. Some of you may even be able to identify the real reason. In my experience it is far from uncommon to find that a man of outstanding merit in respect of the value of his contributions to his subject is one who at a critical point in his development reacted strongly to the stimulus of a particular teacher. Teachers, like other men, indulge in reproduction and the potent professor is one who begets his own kind. The spoken and the written word can fertilize a mind. If there be a place where eugenic considerations should determine behaviour it is surely in the medical schools. Because we are aware of the potency of words, which can be the very essence of character, we are inclined to restrict our teaching to 
technicality although we know full well that this can never be an adequate equipment for those whom we teach, for in medicine knowledge and skill can never be enough; these must be the instruments that compassion and solicitude employ to gain expression. The paediatrician is fortunate in that he deals with the very young, and throughout the animal kingdom these evoke in the adult strong feelings that find their expression in protective action.

Thus it was that Goodhart found continuance in Still, who passed on to The Hospital for Sick Children in Great Ormond Street, with which he was to remain associated for more than 30 years. In 1894 , at the age of 26 , he published the outcome of his first research. Thereafter, until two years before his death in 1941, a steady stream of papers issued from his pen, these serving to record the history of paediatrics during this period and to show the importance of his own contributions thereto. Still's working life was coterminous with the establishment and early development of paediatrics as a separate field of clinical enquiry and practice. In 1906 he was appointed to the chair of the Diseases of Children at King's College, London, the first of its kind in this country, and in $\mathbf{1 9 2 8}$ he was elected as the first president of this Association. In 1933 he presided at the meeting of the International Paediatric Congress in London. He was knighted and appointed as Physician Extraordinary to the King. According to the prevailing standards he was, therefore, a most successful man and the reasons for his success are clearly revealed.

He was genetically well endowed and enjoyed the advantages of a good home and school. He was able to profit from a sound and liberal university education and did so. Entering medicine he chose a calling in accord with his personal attributes, revealed or as yet unexpressed. As a consequence of his encounter with a particular teacher he, being able to respond, reacted to the stimulus thus exerted and entered a field of interest and activity which was about to become closely packed with opportunity for such as he. In his make-up, both genetic and environmental factors operated. He was fortunate in the choice of his parents; he was fortunate also in the choice of the date of his birth, for had he been born 50 years earlier or later the peculiar opportunities for the exercise of his talents which he enjoyed would not have been encountered. Genius is relatively unaffected by time; the commoner general ability which Still possessed required for its expression the environmental opportunity which transmutes the potential into the actual. It is in this sense that each of us is the creation of his environment and since this is ever-changing many able men are denied the chance of discovering the nature and the extent of their ability. The scientist who today enjoys the greatest opportunity for selfexpression and who is advantaged over all others in respect of reward is one who 15 to 20 years ago entered the field of physics, being adequately equipped to do so and being fortunate enough to do so. Yet it could not have been foretold then that the greatest demand on the part of the nation today would be for physicists to work in the atomic field. Manifestly an organization that can advise the as yet unconceived is required.

There are three other facets to Still's personality which must attract the attention of those who would model themselves upon him. He developed into a most accomplished public speaker, using words cleverly to bedeck ideas. This acquisition is most valuable when, as in Still's case, the ideas themselves are sound and constructive. With it a man can render great service. Still associated himself with a number of organizations which in their several ways shared his interests and purposes-Dr. Barnardo's Homes, the Society for Waifs and Strays, and the National Association for the Prevention of Infant Mortality. By doing so he extended the influence of medicine upon social affairs and in his own way did much to secure the intelligent collaboration of the general public, without which the efforts of the medical profession must remain largely fruitless. He wrote verse, by means of which he could explore his own mind and reveal his innermost thoughts without the impediment of self-consciousness. In his Life's Aftermath there is the complete picture of the man whom, with so much reason, we now praise.

When I shall die and in the quiet earth Am laid to rest,

Will there remain some breath of aftermath Of worst or best

Some potency of evil or of good, Its source unguessed,

From words or deeds, remembered or forgot, A life's bequest?

God in his mercy grant that all the wrong May cease to be,

Not only be forgotten but blotted out, That so of me

Shall nothing live that might work others ill, No legacy

Of harm to lead one single soul astray, -Thus may it be

When I shall die.

In these lines are displayed the man's humility, his sense of responsibility, his faith, his hopes, the qualities that lay at the root of his actions. He was outstanding as a physician in his day because of his intellectual ability, his diligence, his skill and his 
scholarship; but above all else, because he was a man of great charity. From his example every one of us can learn and profit much.

With the passing of time, as those who knew him personally themselves depart, the influence that he will continue to exert will stem in increasing measure from his published books and papers and some of these will become part of the very texture of the subject of paediatrics itself. Ultimately they will come to possess only a historical interest since they deal for the most part with topics the importance of which is already diminishing as knowledge expands and problems are solved to become replaced by others. Happy and fortunate indeed is the man who at the end of his life can say that every one of the several hypotheses he constructed in his younger days, perfectly reasonable and logical in their time, accounting for all that was then known, has been destroyed and replaced, for this means that the the search for understanding has continued to be eager. It means also that the younger men who have succeeded in overturning his conclusions can see further and deeper into the nature of things because they stand on the shoulders of their predecessors. There is great joy to be found in this notion of continuity in the chain of which one may hope to become a link.

Still's books and published papers deal for the most part with clinical, curative medicine in the Sydenham tradition. His interests were entirely in accord with the stage of development that paediatrics had then reached and equally in accord with the needs of the time. In reading those which were readily accessible to me, ample evidence of the acuteness of his powers of observation, of his ability to describe that which he observed and to provide a reasonable explanation of its nature and causes was to be found. Because of my own peculiar interests, I sought for evidence concerning his concepts of disease causation and was greatly pleased when I encountered in his third, and possibly his most permanent, paper on a form of chronic joint disease in children, evidence that he had considered such variables as nutrition, poverty, exposure to insanitary conditions, and the sex of the patient as possible factors in aetiology. I was interested because I wished to discover to what extent Still was aware of the growth of the notions that were ultimately to lead to the inception of two new academic disciplines, those of child life and health and of social medicine.

To me it seems that the development of paediatrics, which, as Still remarks in the introduction of his history of the subject, came to include not only all that is concerned with the sick child, but also the care of the health of the child, at any rate during the first two or three years of life, was together with the development of psychiatry, mainly responsible for the beginnings of a revolutionary change in medical thought and action.

Doubtless a variety of causes operated in the creation of paediatrics as a special branch of medicine. That disease in children presented features peculiar to this age group had been recognized as far back in medical history as Hippocrates himself, but $I$ understand that in this country it was not until about the beginning of the present century that certain opinions had become widely held-that the child was an asset of great worth to the nation, that the high peak of mortality in the first year of life could be removed by the exercise of control over its causal agencies through the application of knowledge then becoming available, and that the specialization in the medical field that was yielding such great harvests of new knowledge and of new power could with advantage be extended to cover the diseases of children. But to my mind the most important aspect of this development was that it implied that it has been perceived that different categoriesbiological and social-within the population had different medical needs and that for the satisfaction of these different branches of medicine must be developed. Paediatrics was to be the medicine of a biological category. This being accepted, it followed inevitably that there should develop, in relation to this category, a health-promotive aspect of the subject with its emphasis placed upon the medical needs of the healthy child. In the medical field generally this dichotomy into curative and health-promotive divisions has resulted in two distinct organizations-that of the National Health Service, which, in fact, is concerned not with the promotion of health, but with its restoration, and that of the medical services of central and local authority, which in respect of policy are positively health promotive. In the field of child medicine this division is by no means so clear cut. For example, a professor of child life and health may or may not be actively interested in matters relating to the biological category-the child-but he is invariably involved in the diagnosis and treatment of the illnesses of individual children in series. The child welfare clinics of local authority likewise deal with the maintenance of the health of the child as a biological category and as an individual, the lessons learnt from the study of the group being applied to the affairs of the individual and vice versa. It therefore seems to me that this branch of medicine, in its development, is ahead of those branches which deal with the adult. That this is 
so is due, in my view, to certain differences that distinguish the mature from the immature, differences which with the passing of time have tended to gain greater emphasis.

In my time the rate and direction of the development of that corpus of knowledge and of that constellation of skills which we know as medicine have, in the main, been determined by discoveries in the physical sciences, by the impact of these discoveries upon medical thought and by the application of the concepts attached to them in medical action. The living organism came to be looked upon as something that could be understood in terms of biophysics and chemistry. The individual came to be regarded as an integrated aggregate of highly specialized component parts, tissues, organs and organ-systems, mutually interdependent and none of them in itself self-sufficient, each making its own particular contribution to the well-being and continuance of the whole. The physical and chemical nature of these various contributions was revealed. Fault in any one of these component parts reflected in its functioning led to the disruption of the whole system. A disease-evoking agency evoked its effects by acting upon a particular component part in such a way as to lead to its malfunctioning. This being the prevailing concept of the nature of man and of disease it followed that diagnostic and therapeutic procedures took the form of attempts to identify the faulty part and to repair its functioning. The profession became particulate in its organization and interests, a particular specialty being restricted to one organ, to one system or to one anatomical region of the body. The inevitable consequence of this specialization was that the patient entering the sphere of the specialist, the hospital sphere, tended to cease to be a person and to become a case. Thus specialization became the dominant pattern of this 'scientific' medicine, in the development of which the hospital evolved as the chief therapeutic and research institution, thus exemplifying in its depersonalized and fractionated services and its highly refined procedures the ideals and principles of the scientific approach to the problem of disease. This specialization has undoubtedly led to great advances in knowledge of structure and function and to great developments in the techniques of diagnosis and therapy. For the specialist of this kind there will always be a place within the medical organization. As a result of the manifest advantages that have resulted from this specialization within the medical profession, a change in the hierarchical order within the profession occurred. In this the specialist ranks high, the generalist low. The medical scientist-physicist, chemist, physiologist, bacteriologist and the likeranks higher than the clinician.

Latterly, however, there has been spreading the view that medical care stemming solely or mainly from strictly physical and depersonalized considerations is not satisfactory for the reasons that the notions that the individual can be adequately described in physical and chemical terms and that disease is due to the fault in the functioning of a part no longer constitute a working hypothesis that accounts for all the observed facts. The individual is more than an aggregate of harmoniously interrelated specialized parts. He has to be considered not only as an organism living in an external physical environment, but also as a member of a particular society and as the product of a particular culture, for it has been recognized anew that psychological and social factors no less than biophysical play their part in disease causation. It is now remembered that in the magico-religious forms of medicine which preceded our secular scientific variety the medicine man, knowing nothing of the medical sciences, nevertheless was able to achieve much because he paid attention to the bearing of the emotions, attitudes, social pressures and supports upon sickness and health. It is remembered, too, that the great therapists of the past have been those who treated their patients as people responding to complex social pressures. It is not that the clinicians of today are unaware of these things; medicine developed as it did because the physical sciences, nurtured by the needs of a society such as our own, developed earlier and more rapidly than did the biological and the social. The newer function of the almoner and her changed relationship with the clinician are indications that the latter recognizes his need for this particular form of reinforcement. It has been his lack of knowledge of the concepts, content and methodology of the social sciences that has created the opportunity for the almoner to cultivate the view that she is not an instrument used by him for the securing of knowledge of value in diagnosis, therapy and prognosis, but that he and she are partners of near equality.

At this point I must make it clear that many of the opinions I express are tentative. There was a time when to my opinions I personally ascribed considerable value, but with the passing of the years my confidence has waned and I am relieved to find that they are not precious to me, that they have not undergone that strange form of degenerative hardening that transforms opinion into conviction. And so it may well be that my interpretation of events is exceedingly faulty owing to the inadequacy of my knowledge of them. But it does seem to me 
that in a few of the branches of medicine, and in paediatrics and psychiatry especially, specialization has not led to the development of a system of thought and action derived almost exclusively from the physical sciences. In paediatrics I suppose that this has been so because of certain differences between the adult and the child as patients. Up to a point, but only up to a point, can the child be considered as an individual organism, for so very obviously he is not independent. The umbilical cord of dependency is not cut at birth; it continues to unite the offspring to its parents for 15 years or more. In a very real sense the sick child is not a sick individual but a sick family and it is within the family, as often as not, that the cause is to be sought and to the family that treatment is given. The family is not merely a small self-contained aggregate of organically interrelated individuals; it is representative of and is the product of a particular form of social organization and of a stratum thereof and, moreover, it is the product of a particular culture. Beliefs fashion attitudes and attitudes behaviour and today there is abundant evidence to show beyond all doubt that in the social structure and in the culture there are to be discovered forces which in their action yield disease. A human being is an integrated unit but one with fears, aspirations, goals, despairs and compulsions which profoundly affect the state of his health, and the line that formerly divided his organic processes from his emotional and social life is now seen to be an artifact.

You, therefore, unlike your professional brethren whose cases need larger beds, have never been able to disregard the psychosocial factors in disease causation and in therapy and so have occupied, and still occupy, a strategic position for the integration of the social disciplines with medicine. This is particularly true today, for recent years have witnessed the swift growth of the behavioural sciences in respect of scientific concept and of skill and there is much deriving from them that has its applications in medicine. In my view it is in the development of this integration of medicine and the social sciences that lies the chance for medicine to make its greatest contribution to society. We as a people are dedicated to the task of building a world from which all the forces that assail human dignity and goodness shall have been eliminated. Preventable disease is regarded as a barrier that must be overthrown. If social and cultural factors make their contributions to the corruption of human perfection these must be identified and brought under control. Since it is upon the profession of medicine that society relies for such action stemming from expert knowledge, it follows that the profession must equip itself with the appropriate interests and busy itself with the acquisition of the relevant knowledge and skill.

To others, if not to you, this must necessarily involve a great extension of the medical sphere since this will come to include problems that transcend the traditional organized medical knowledge that now comprises the equipment of its practitioners. It implies that there must come into being an alliance and collaboration between medicine and those disciplines which are concerned with behaviour from the standpoint of group processes and cultural dynamics. The growth of medicine in the past has taken this very form; the great advances have been the outcome of the fusion of medicine and chemistry, medicine and physics, medicine and mathematics, and the like. In the intellectual field the hybrid produced by the mating of two separate disciplines is remarkable for its vigour.

The practice of medicine must necessarily be conducted within a social setting and involves the establishment by the doctor of such relationship with the patient, and in your case with the patient's family, that cooperation between the two in diagnostic and therapeutic procedures becomes possible. Medicine is one of the series of institutions that together comprise a culture; it has its own corpus of knowledge and techniques, values, beliefs, ideology, rituals and symbok, but they are essentially in accord with those of the other institutions, for example, religion, art, economy, law. In a society such as ours no individual comes into contact with the whole of its culture and so it happens that within the population there are a number of subcultural groups. Such matters are self-evident, but their bearing upon the practice of medicine is not.

When individuals belonging to widely different sub-cultural groups are brought into contact, as in the doctor-patient relationship, the efficacy of medical intervention is increased if the doctor is aware of the extent to which the patient's behaviour is influenced by cultural factors and if he is prepared to modify his own procedures so as to bring them into line, as far as possible, with the patient's expectations, which are born of his own concepts concerning himself and his complaint, these in turn being acquisitions from the sub-culture which moulded him. The doctor himself is likewise a socially conditioned person whose intervention takes place in a social system that defines the role he plays and provides the set of values that determines his behaviour. The roles played by 'the way of life', the social organization, the prevailing beliefs, in the establishment of an optimal relationship between doctor and patient are most clearly revealed when a representative of our culture and of its 
secular scientific medicine is introduced into an 'undeveloped' country. In his case it is imperative that he should clearly recognize the social and cultural forces that have shaped his thinking and behaving and that he should know sufficient of the social and cultural forces that have yielded his patients, so utterly different from himself. Without such knowledge the value of the service he renders is greatly diminished.

Penicillin and paludrin do not combat the supernatural forces which, according to certain systems of belief, are the real causal agencies of disease. There is no panacea for superstition in our pharmacopoea, yet the terror that can stem therefrom can destroy.

Such knowledge can be, and often is, acquired through experience, but it can be most thoroughly developed through formal teaching in the psychological and social sciences with enough philosophy to enable the student to understand and deal with problems of value judgments.

Medical education to-day almost completely disregards the Hippocratic concern for health; it is essentially a recapitulation of the historical development of 'scientific' medicine during the last four hundred years and its spirit, its basic philosophy and its goal have not changed since Sydenham's time, though its subject matter has become greatly expanded. Its prime purpose is to teach the student to recognize disease, to fit this into a nosological category, and to exhibit the currently appropriate therapeutic action. The student is trained to take his place between the diagnostic laboratories on the one side and the great pharmaceutical manufactories on the other. Disease and death become his pivotal interests. The atmosphere of the hospital and clinic might have been specially designed to obliterate the personalities of those who enter them. The patient, stripped of every identifying symbol and bereft of his group memberships, thus becomes a case of a particular pathological condition. He is an example of a disease rather than a diseased person, that is one suffering from or complaining of disability, pain and anxiety, his behaviour having been changed thereby. Yet in open society it is with people that the doctor must deal.

A discontent with the existing curriculum has been growing rapidly of late and efforts are constantly being made to improve upon it. Unfortunately the overwhelming majority of those involved in these deliberations is composed of medical scientists and of teachers of the clinical subjects whose opinions concerning medical education are all too frequently an expression of preferences in accord with their own personal experience. For the most part they plan to produce scientists and clinicians, better equipped than themselves but accoutred with exactly the same concepts and attitudes. For my part I think that nothing short of a complete change of interest and aim can produce a curriculum in harmony with the needs of the times. It has to be accepted, of course, that because disease is so prevalent the medical student must be so trained that he can play his part in attempts to cope with it by means of accurate diagnosis and skilful treatment. But he should not be encouraged to cultivate the view that it is from such activities that the greatest satisfaction is to be derived, that the cure of disease is his prime function. His reasonable delight in the scientific aspects of pathology and therapeutics should not be allowed to blind him to the fact that disease is the great enemy of achievement and is to be deplored and overcome.

History shows that this revolution very nearly occurred following the First World War, during which the destruction of humanity had been so vast in scale that in this country, as elsewhere, it came to be considered necessary to save life wherever possible. A Ministry of Health was created 'for the purpose of promoting the health of the people' and a number of public health services were initiated for the care of the mother and infant, the school child and the like. But what in fact happened was an extension of the medicine that was; there was no radical change in the purview of medicine; and so it is that the present National Health Service is really nothing more than an extension of that which previously existed, a further expansion of governmental initiative in the medical field.

These events were mirrored in the universities during Still's lifetime. Thus, in Edinburgh, lecturers in the diseases of children were first appointed in 1885 when the subject was recognized by the University. But by 1930 , when funds for the endowment of a chair became available, the subject to be professed had become Child Life and Health. To that chair Charles McNeil, then physician to the Royal Edinburgh Hospital for Sick Children, was appointed. Whether or not this change in title from lecturer in the diseases of children to professor in child life and health was in any sense an immediate and significant movement in emphasis from disease to health, from the child as an individual to the child as a biological category, I am not competent to say; but it is certainly true to say that today in Edinburgh the activities of the university Department of Child Life and Health are in accord with its title. Since this is what has happened throughout the universities of the country it can be concluded that the revolution that was threatened but which did not occur in open society has occurred, if not in academic 
medicine generally, certainly in your own branch, even though it has not become complete. It is in your branch (and in psychiatry) that the patient is studied as a total person in relation to his total external world. In the psychiatric field it was when the futility and folly of treating a specific disease rather than the whole man was recognized that the subject began to develop.

That there is no academic chair of Adult Life and Health or of Senescent Life and Health is indicative of the present aim, scope and content of medicine and of the bias in medical education. That the hospital ward is the place where medicine is taught is equally indicative of its aim. I wish to submit that upon those of you who bear titles which include the word health and who are involved in the teaching of the medical student, and therefore in the reform of the medical curriculum, a heavy responsibility is laid. You know that in considerations of aetiology the social milieu cannot be disregarded; you know the extent to which social supports and pressures affect the well-being of the individual; you know the effect of ethnocentrism upon judgment; you know that the doctor-patient relationship must be extended to one of doctor and community; you know how unwarranted is the assumption that reason is the controlling and determining force in human behaviour and that emotions, customs, cultural patterns and other non-rational factors cannot be disregarded when seeking diagnostic information. You know that the notion of a fixed innate human nature, common to all, is utterly mistaken and that different sub-cultural groups within the population have cultivated different patterns of response to the same situation. You have reason to know these things better than most of your colleagues active in other fields.

If then, in your case a certain knowledge of sociology, social psychology, cultural anthropology, demography, for example, is or would be of considerable advantage to you, you can be certain that it would be of equal advantage to all within the general field of medicine. If this be so, then the question arises as to the means and methods that require to be made available. In the modern world most problems are complex and require for their investigation a combination of disciplines. At the level of W.H.O. problems relating to health and disease are tackled by teams which are composed of medical and social scientists. In many of the American medical schools social scientists are members of the medical faculty and in conferences of this kind social scientists regularly participate. I doubt very much that such an arrangement is entirely satis- factory; there are certain difficulties. It is very rare, as yet, for a social scientist to become interested in problems with medical aspects of major importance. The cultural anthropologist, for example, is much more likely to be interested in and to know more of Polynesia and the quaint customs of its people than of Pimlico. Moreover, these social scientists, like ourselves, have developed a technical language comprehensible only to themselves so that intercommunion tends not only to be difficult but even misleading, for words used by them and by us are given different connotations. Certainly, if an alliance is to become effective, medical and social scientists must live and work together if they are to comprehend each other's concepts and methodologies.

Personally I should prefer that these subjects should be taught by medically qualified teachers who had specialized in them whilst members of the staff of a department of social medicine, where these subjects can most appropriately be accommodated. Be this as it may, what matters is that the student of medicine should be brought into contact with these subjects offered as part of the medical curriculum itself. This would not necessarily mean that to an already overloaded curriculum still more would be added. If the curriculum were reorientated a good deal of that which is now included could be discarded. Moreover, if the student's education was organized around the central theme of health as a prerequisite to achievement, learning would surely become more meaningful and therefore easier, as would also teaching.

I now must make an end to what to me has been somewhat of an ordeal. You will understand that it is quite impossible for anyone to decline an invitation to deliver a memorial lecture of this kind. It is a great honour to be permitted to occupy this position. It is also a challenge that must be accepted. To be selected by one's peers is to be loaded with a responsibility that cannot be shirked. I ask you to overlook my deficiencies, remembering only that I am both proud and grateful to have enjoyed the privilege of joining with the members of this Association in this ceremony of remembrance of a man who in his day was much concerned with medical education and who would most certainly have been aware of the urgent need for a new outlook. So much reliance is now placed upon medical opinion by those who translate recommendation into action directed towards human betterment and social amelioration that at no time in history has it been more important that this opinion should be soundly based on knowledge as comprehensive as possible. 